\title{
The Optimization of Alkali-Catalyzed Biodiesel Production from Camelina sativa Oil Using a Response Surface Methodology
}

\author{
Jie Yang ${ }^{1}$, Kenneth Corscadden ${ }^{1}$, Quan Sophia $\mathrm{He}^{1^{*}}$ and Claude Caldwell ${ }^{2}$
}

${ }^{1}$ Department of Engineering, Faculty of Agriculture, Dalhousie University, Truro, NS B2N 5E3, Canada

${ }^{2}$ Department of Plant and Animal Science, Faculty of Agriculture, Dalhousie University, Truro, NS B2N 5E3, Canada

\begin{abstract}
Camelina sativa oil is considered a promising feedstock for biodiesel production. Response Surface Methodology (RSM) was used to optimize camelina biodiesel production by an alkali-catalyzed transesterification process. The effects of independent factors (temperature, time, molar ratio of methanol/oil, and catalyst concentration) on dependent variables (product yield and fatty acid methyl ester (FAME) yield), was investigated. Mathematical regression models were developed for prediction of the biodiesel product yield and FAME yield. The camelina biodiesel product yield (97\%) and FAME yield (98.9\%) were achieved at the optimal reaction conditions of $38.7^{\circ} \mathrm{C}$ reaction temperature, $40 \mathrm{~min}$ reaction time, 7.7 molar ratio of methanol/oil, and $1.5 \mathrm{wt} . \%$ catalyst concentration.
\end{abstract}

Keywords: Camelina sativa; Transesterification; Biodiesel; Response surface methodology; Optimization

\section{Introduction}

Over past decades, the growth of the world population and industrialization has led to an increasing consumption of petro-fuels, resulting in a dramatic decline in petroleum reserves. The extensive use of fossil fuels also caused severe atmospheric pollution and growing concerns about global warming due to the emissions of greenhouse gases [1]. From the socioeconomic point of view, the political environment in the greatest oil-exporting region is unstable as well. These combined factors are driving researchers and industrial practitioners to develop renewable and sustainable fuel alternatives [2]. Biofuels have recently attracted great interest as one of the promising substitutes for petrofuels. It has been estimated that biofuels will make up $80 \%$ of the overall liquid fuels growth from 2010 and 2035 in the United States [3].

Biodiesel is one of such biofuels that is comparable to the conventional petro-diesel and is compatible in various applications such as trucks and automobiles, farm vehicles, and stationary power and heat generation [4]. It is renewable, biodegradable, environmentally innocuous, and relatively safe to handle due to its high flash point [5]. Biodiesel is typically defined as a mixture of fatty acid alkyl esters obtained through a transesterification process, in which triglycerides from vegetable oils, animal fats, and even waste cooking oils react with alcohol in the presence of a catalyst. Currently, more than $95 \%$ of biodiesel worldwide is derived from edible vegetable oils such as soybean and canola oils [6]. However, this competes with the food and feed supply industry, raising a heated debate about "Fuel vs. Food". On the other hand, the cost of feedstock accounts for $75-85 \%$ of total biodiesel production costs; thus, the price of biodiesel is generally higher than that of petroleum diesel [7]. This has been the major barrier to its commercialization on a large scale. Therefore, it is important to develop non-edible and/or low-cost oil crops that meet certain requirements, including low agricultural inputs, high oil yield, and favorable fatty-acid compositions [8,9], to increase the overall economic viability of biodiesel production.

Recent research has recognized camelina (Camelina sativa $\mathrm{L}$. Crantz), belonging to the Brassicaceae family and known as false flax or gold-of-pleasure, as a promising and sustainable oilseed crop for biodiesel production in North America [2,10,11]. Camelina seeds have a fairly high oil content (35-43\% on a dry matter basis) [12,13]. More importantly, it requires low cultivation inputs, has a short growing season, and is tolerant to drought, cool weather and insect pests [14,15] However, there is limited research on the synthesis of camelina biodiesel and the optimization of its production [16,17]. Many relevant studies have focused on feedstocks such as soybean, canola, and sunflower, etc. [18-20]. In particular, most of the studies on optimizing biodiesel production used a stepwise method (changing one separate factor at one time), which is not capable of assessing the interaction between each factor in the transesterification process $[21,22]$.

In this study, camelina oil was converted into biodiesel through an alkali-catalyzed transesterification process, the effects of various reaction parameters on the yield/quality of the resulting biodiesel were investigated, and the optimal reaction conditions were obtained within our experimental scope. Response Surface Methodology (RSM), a powerful tool in the optimization of physical and chemical processes $[23,24]$, was employed to evaluate the effect of independent factors on the reaction response and to determine the maximum reaction response under the optimal reaction conditions. So far we have found no such investigation reported. The outcomes from the present study would offer helpful knowledge in the eventual scale-up process for camelina biodiesel production.

\section{Materials and Methods}

\section{Materials}

Camelina oil used for biodiesel synthesis was cold pressed from Camelina sativa L. Crantz CDI007 seeds grown in Canning, Nova Scotia, Canada. Potassium hydroxide $(>85 \%)$ in the form of pellet, analytical grade methanol ( $>99 \%)$, calcium chloride anhydrous and

*Corresponding author: Quan Sophia He, Department of Engineering, Faculty of Agriculture, Dalhousie University, Truro, NS B2N 5E3, Canada, Tel: 902-893-6180; E-mail: quan.he@dal.ca

Received May 12, 2015; Accepted June 26, 2015; Published July 01, 2015

Citation: Yang J, Corscadden K, He QS, Caldwell C (2015) The Optimization of Alkali-Catalyzed Biodiesel Production from Camelina sativa Oil Using a Response Surface Methodology. J Bioprocess Biotech 5: 235 doi:10.4172/21559821.1000235

Copyright: (c) 2015 Yang J, et al. This is an open-access article distributed under the terms of the Creative Commons Attribution License, which permits unrestricted use, distribution, and reproduction in any medium, provided the original author and source are credited. 
hexane (>99\%) were purchased from Fisher Scientific Ltd., Canada A standard reference solution of camelina methyl esters (GLC 937, >99\%) was purchased from $\mathrm{Nu}-\mathrm{Chek}$ Prep. Inc. USA.

\section{Transesterification process}

A typical camelina biodiesel synthesis was as follows: $50 \mathrm{~g}$ of camelina oil was added to a $300 \mathrm{~mL}$ flask and placed in a water bath at a set temperature. A pre-calculated amount of methanol solution containing completely-dissolved $\mathrm{KOH}$ was added to the camelina oil. The reaction was carried out with a constant $300 \mathrm{rpm}$ agitation rate and stopped once the preset time was reached. The reaction mixture was transferred to a separatory funnel and allowed to stand for $30 \mathrm{~min}$ for phase separation, and then the glycerol layer under the crude biodiesel was drawn off. The crude biodiesel remaining in the separatory funnel was washed by a few batches of distilled water until the water layer became completely translucent. Camelina biodiesel (after the water washing) was dried by adding calcium chloride and then centrifuged to remove the water-saturated calcium chloride, giving purified biodiesel for further analysis.

\section{Product analysis}

There are two ways to express the yield of biodiesel obtained from a transesterification process: product yield and FAME yield. The product yield shown in Equation (1) indicates the quantity of the biodiesel produced with respect to the raw oil feed. The FAME yield in Equation (2) is determined by the amount of FAME with respect to the resulting biodiesel, which is an indicator of the quality of the biodiesel.

$$
\begin{aligned}
& \text { Product yield }(\%)=\frac{\text { mass of biodiesel }}{\text { mass of oil }} \times 100 \% \\
& F A M E \text { yield }(\%)=\frac{\text { mass of FAME }}{\text { mass of biodiesel }} \times 100 \%
\end{aligned}
$$

The FAME yield was determined by using an Agilent 7890A Gas Chromatography (GC) equipped with a flame ionization detector (FID) and an Agilent DB-23 column (50\%-Cyanopropyl-methylpolysiloxane; 30 -m length $\times 0.25$-mm internal diameter $\times 0.25 \mu \mathrm{m}$ thickness; high polarity). The carrier gas was helium and the oven temperature was initially set at $190^{\circ} \mathrm{C}$ and then was increased to $250^{\circ} \mathrm{C}$ at a heating rate of $40^{\circ} \mathrm{C} / \mathrm{min}$, remaining at $250^{\circ} \mathrm{C}$ for $3.5 \mathrm{~min}$. Sample preparation for GC was as follows: $25 \mathrm{mg}$ of biodiesel was dissolved in $1 \mathrm{~mL}$ of hexane solvent, and $1 \mu \mathrm{L}$ of the sample solution was injected into the GC with a split ratio of 40:1 for FAME identification and quantification. The fatty acid methyl esters were identified by comparing their specific retention times to those of a standard reference solution of camelina methyl esters.

\section{Experimental design}

Central Composite Design (CCD), one of the most commonly used response surface methodology designs, was applied in this optimization study. The four independent variables were reaction temperature $\left({ }^{\circ} \mathrm{C}\right)$, reaction time $(\mathrm{min})$, molar ratio of methanol/oil, and catalyst concentration (wt.\% with respect to oil). Three levels for each variable were determined based on our preliminary experiments as well as relevant research reported in the literature. The coded symbols, ranges, and levels of the four independent variables are given in Table 1. The product yield and FAME yield were selected as responses for assessing the effect of each variable, interactions between variables and optimizing experimental conditions. This three-level-four-factor CCD design generated 31 experiment combinations, including 7 center points, 8 axial points and 16 fact points. All of these combinations were replicated twice. The experimental data thus obtained were analyzed via Design Expert version 6.0.2 and then fitted to the following second-order polynomial equation in Equation (3) $[25,26]$ :

$$
\mathrm{y}=\beta_{0}+\sum_{i=1}^{k} \beta_{i} \chi_{i}+\sum_{i=1}^{k} \beta_{i i} \chi_{i}^{2}+\sum_{i} \sum_{<j=2} \beta_{i j} \chi_{i} \chi_{j}
$$

Where $y$ is the response, $x_{i}$ and $x_{i}$ are the coded independent variables, $\beta_{0}$ is the constant intercept coefficient, $\beta_{\mathrm{i}}$ is the linear coefficient, $\beta_{\mathrm{ii}}$ is the quadratic coefficient, and $\beta_{\mathrm{ij}}$ is the interaction coefficient. A $95 \%$ significance level was used for the analysis of variance (ANOVA) to select the model terms. The three-dimensional response surface plots were obtained as well (Table 1).

\section{Results and Discussion}

\section{Regression model development and ANOVA analysis}

In a transesterification process, the quantity and quality of the resulting biodiesel are influenced by a number of variables, mainly including the reaction temperature, reaction time, molar ratio of methanol/oil, and catalyst concentration. Table 2 lists the complete design matrix (31 experimental runs) and the corresponding response data (product yield and FAME yield) based on these four independent variables (temperature, time, molar ratio of methanol/oil, and catalyst concentration). The experimental values were data obtained from experiments, and the predicted values were generated from the mathematical regression models. The quadratic regression model was suggested by Design Expert for the two responses, and the following regression models were developed:

The product yield regression model for the coded levels is expressed in the below Equation (3):

$\mathrm{Y}_{\text {Product vield }}=96.02+1.12 \mathrm{X}_{1}+1.15 \mathrm{X}_{2}+0.44 \mathrm{X}_{3}+1.39 \mathrm{X}_{4}-0.86 \mathrm{X}_{1}^{2}-$ $0.08 \mathrm{X}_{2}^{2}-0.13 \mathrm{X}_{3}^{2}-1.19 \mathrm{X}_{4}^{2}-1.08 \mathrm{X}_{1} \mathrm{X}_{2}-0.68 \mathrm{X}_{1} \mathrm{X}_{3}-2.57 \mathrm{X}_{1} \mathrm{X}_{4}-0.88 \mathrm{X}_{2} \mathrm{X}_{3}$ $-1.14 \mathrm{X}_{2} \mathrm{X}_{4}-0.64 \mathrm{X}_{3} \mathrm{X}_{4}$

The FAME yield regression model for the coded levels is described in the below Equation (4):

$\mathrm{Y}_{\text {FAME yild }}=97.33+1.70 \mathrm{X}_{1}+0.76 \mathrm{X}_{2}+1.11 \mathrm{X}_{3}+3.54 \mathrm{X}_{4}-1.05 \mathrm{X}_{1}^{2}+$ $0.12 \mathrm{X}_{2}^{2}-0.63 \mathrm{X}_{3}^{2}-2.23 \mathrm{X}_{4}^{2}-0.10 \mathrm{X}_{1} \mathrm{X}_{2}+0.37 \mathrm{X}_{1} \mathrm{X}_{3}-1.95 \mathrm{X}_{1} \mathrm{X}_{4}-0.26 \mathrm{X}_{2} \mathrm{X}_{3}-$ $0.61 \mathrm{X}_{2} \mathrm{X}_{4}-0.85 \mathrm{X}_{3} \mathrm{X}_{4}$

Where reaction temperature: $X_{1}$, reaction time: $X_{2}$, molar ratio of methanol to oil: $\mathrm{X}_{3}$, and catalyst concentration: $\mathrm{X}_{4}$.

The coefficients of the regression model terms were determined by the least squares method. The significance of the linear, quadratic, and interaction model terms and their estimated coefficients are listed in Table 3.

To examine how well the regression $\mathrm{n}$ models fitted the experimental data, the Fisher F-test values (F-value), p-value, lack of fit, regression coefficient $\mathrm{R}$-square $\left(\mathrm{R}^{2}\right)$, and adjusted R-square $\left(\operatorname{Adj} \mathrm{R}^{2}\right)$ were evaluated by the analysis of variance (ANOVA) and are summarized in Table 4. Generally, a well-fitted regression model indicates a successful correlation between the response and independent variables [27].

As seen in Table 4, F values of 18.89 and 21.93 for the two models, were both greater than 3.19 , and the p-values were lower than 0.0001 , demonstrating the validity of the developed quadratic models. 
Citation: Yang J, Corscadden K, He QS, Caldwell C (2015) The Optimization of Alkali-Catalyzed Biodiesel Production from Camelina sativa Oil Using a Response Surface Methodology. J Bioprocess Biotech 5: 235 doi:10.4172/2155-9821.1000235

Page 3 of 8

\begin{tabular}{|c|c|c|c|c|}
\hline Variables & Symbol code & \multicolumn{2}{|c|}{ Levels } \\
\hline & & $-\mathbf{0}$ & $\mathbf{1}$ \\
\hline Temperature $\left({ }^{\circ} \mathrm{C}\right)$ & $\mathrm{X}_{1}$ & 30 & 40 & 50 \\
\hline $\operatorname{Time}(\mathrm{min})$ & $\mathrm{X}_{2}$ & 20 & 30 & 40 \\
\hline Methanol/oil molar ratio & $\mathrm{X}_{3}$ & $6: 1$ & $8: 1$ & $10: 1$ \\
\hline Catalyst concentration (wt.\%) & $\mathrm{X}_{4}$ & 0.75 & 1.25 & 1.75 \\
\hline
\end{tabular}

Table 1: Independent factors and levels used for the central composite design (face-centered).

\begin{tabular}{|c|c|c|c|c|c|c|c|c|c|c|c|c|}
\hline \multirow[b]{2}{*}{ No. } & \multirow[b]{2}{*}{$x_{1}$} & \multirow[b]{2}{*}{$x_{2}$} & \multirow[b]{2}{*}{$x_{3}$} & \multirow[b]{2}{*}{$X_{4}$} & \multirow[b]{2}{*}{ Temp $\left({ }^{\circ} \mathrm{C}\right)$} & \multirow[b]{2}{*}{$\begin{array}{l}\text { Time } \\
\text { (min) }\end{array}$} & \multirow[b]{2}{*}{$\begin{array}{c}\text { Molar } \\
\text { ratio }\end{array}$} & \multirow[b]{2}{*}{$\begin{array}{c}\text { Catalyst } \\
\text { (wt.\%) }\end{array}$} & \multicolumn{2}{|c|}{ Product yield (\%) } & \multicolumn{2}{|c|}{ FAME yield (\%) } \\
\hline & & & & & & & & & Exp. value & $\begin{array}{l}\text { Predicted } \\
\text { value }\end{array}$ & Exp. value & Predicted value \\
\hline 1 & 0 & 0 & 0 & -1 & 40 & 30 & 8 & 0.75 & 92.5 & 92.72 & 92.8 & 91.55 \\
\hline 2 & +1 & -1 & -1 & -1 & 50 & 20 & 6 & 0.75 & 92.7 & 92.85 & 88.8 & 89.80 \\
\hline 3 & -1 & -1 & +1 & -1 & 30 & 20 & 10 & 0.75 & 86.7 & 87.24 & 85.0 & 86.73 \\
\hline 4 & 0 & 0 & 0 & +1 & 40 & 30 & 8 & 1.75 & 95.5 & 95.50 & 97.7 & 98.63 \\
\hline 5 & 0 & 0 & 0 & 0 & 40 & 30 & 8 & 1.25 & 95.3 & 96.02 & 97.8 & 97.33 \\
\hline 6 & 0 & +1 & 0 & 0 & 40 & 40 & 8 & 1.25 & 96.1 & 97.08 & 98.3 & 98.21 \\
\hline 7 & +1 & +1 & +1 & +1 & 50 & 40 & 10 & 1.75 & 91.2 & 90.15 & 97.7 & 97.25 \\
\hline 8 & -1 & -1 & -1 & -1 & 30 & 20 & 6 & 0.75 & 81.0 & 81.96 & 83.7 & 83.02 \\
\hline 9 & -1 & +1 & -1 & +1 & 30 & 40 & 6 & 1.75 & 96.1 & 97.37 & 97.8 & 97.95 \\
\hline 10 & +1 & -1 & -1 & +1 & 50 & 20 & 6 & 1.75 & 94.1 & 94.03 & 97.1 & 95.89 \\
\hline 11 & +1 & +1 & +1 & -1 & 50 & 40 & 10 & 0.75 & 95.3 & 96.06 & 96.8 & 96.99 \\
\hline 12 & +1 & -1 & +1 & +1 & 50 & 20 & 10 & 1.75 & 93.2 & 94.06 & 96.7 & 97.67 \\
\hline 13 & +1 & 0 & 0 & 0 & 50 & 30 & 8 & 1.25 & 94.7 & 96.27 & 96.8 & 97.98 \\
\hline 14 & -1 & -1 & -1 & +1 & 30 & 20 & 6 & 1.75 & 94.2 & 93.42 & 95.9 & 96.92 \\
\hline 15 & +1 & +1 & -1 & -1 & 50 & 40 & 6 & 0.75 & 97.4 & 97.01 & 92.8 & 92.86 \\
\hline 16 & +1 & -1 & +1 & -1 & 50 & 20 & 10 & 0.75 & 96.8 & 95.42 & 96.3 & 94.97 \\
\hline 17 & 0 & 0 & 0 & 0 & 40 & 30 & 8 & 1.25 & 95.5 & 96.02 & 98.1 & 97.33 \\
\hline 18 & -1 & -1 & +1 & +1 & 30 & 20 & 10 & 1.75 & 95.8 & 96.16 & 98.5 & 97.24 \\
\hline 19 & 0 & 0 & 0 & 0 & 40 & 30 & 8 & 1.25 & 96.3 & 96.02 & 98.9 & 97.33 \\
\hline 20 & +1 & +1 & -1 & +1 & 50 & 40 & 6 & 1.75 & 94.2 & 93.66 & 97.0 & 96.51 \\
\hline 21 & -1 & +1 & +1 & +1 & 30 & 40 & 10 & 1.75 & 96.7 & 96.57 & 97.0 & 97.22 \\
\hline 22 & 0 & 0 & 0 & 0 & 40 & 30 & 8 & 1.25 & 96.7 & 96.02 & 96.6 & 97.33 \\
\hline 23 & 0 & 0 & -1 & 0 & 40 & 30 & 6 & 1.25 & 95.2 & 95.44 & 95.8 & 95.59 \\
\hline 24 & -1 & +1 & +1 & -1 & 30 & 40 & 10 & 0.75 & 92.2 & 92.20 & 89.1 & 89.15 \\
\hline 25 & 0 & 0 & 0 & 0 & 40 & 30 & 8 & 1.25 & 96.3 & 96.02 & 95.7 & 97.33 \\
\hline 26 & 0 & -1 & 0 & 0 & 40 & 20 & 8 & 1.25 & 95.6 & 94.79 & 97.0 & 96.69 \\
\hline 27 & 0 & 0 & +1 & 0 & 40 & 30 & 10 & 1.25 & 96.4 & 96.33 & 97.9 & 97.81 \\
\hline 28 & 0 & 0 & 0 & 0 & 40 & 30 & 8 & 1.25 & 96.9 & 96.02 & 96.7 & 97.33 \\
\hline 29 & -1 & 0 & 0 & 0 & 30 & 30 & 8 & 1.25 & 95.5 & 94.04 & 96.1 & 94.58 \\
\hline 30 & -1 & +1 & -1 & -1 & 30 & 40 & 6 & 0.75 & 91.3 & 90.45 & 86.2 & 86.49 \\
\hline 31 & 0 & 0 & 0 & 0 & 40 & 30 & 8 & 1.25 & 95.6 & 96.02 & 96.5 & 97.33 \\
\hline
\end{tabular}

Temp: temperature; Molar ratio: molar ratio of methanol to oil; Catalyst: catalyst concentration; min: minute.

Table 2: The central composite design (face-centered) of four independent factors and the corresponding experimental and predicted values of responses.

Alternatively, the lack of fit that compares the residual error to the pure error is another good indication of the model validity. Generally, a regression model exhibits lack of fit when it cannot adequately describe the relationship between the dependent variable and the independent factors. Therefore, a non-significant lack of fit is desirable. Here, the lack of fit for product yield and FAME yield was $0.0520>0.05$ and $0.6010>0.05$, respectively, indicating that the lack of fit of the two regression models was not significant and the models fitted well to the experimental data. As for the regression coefficient $\mathrm{R}^{2}$, the closer to 1 it is, the better the model fits the experimental data. Adj $\mathrm{R}^{2}$ is the adjusted version of $\mathrm{R}^{2}$ and it is commonly used to represent the strength of correlation between the predicted values determined by the regression models and the actual values from the experimental runs [28]. In our work, both the Adj $\mathrm{R}^{2}$ values for the product yield (0.8981) and the FAME yield (0.9071) implied a strong correlation between the predicted data and the experimental data. Figure $1 \mathrm{a}$ and $1 \mathrm{~b}$ further depicted how well the observed values of the two responses fitted to their corresponding predicted values against the regression line (with the slope of 1).

Based on the above combined facts, it is concluded that the quadratic regression models developed for both product yield and FAME yield were valid and showed a satisfactory correlation between the responses and the independent variables (Table 4 and Figure 1). 
Page 4 of 8

\begin{tabular}{|c|c|c|c|c|c|c|c|c|}
\hline \multirow[b]{2}{*}{ Factor } & \multicolumn{4}{|c|}{ Product yield (\%) } & \multicolumn{4}{|c|}{ FAME yield (\%) } \\
\hline & $\begin{array}{l}\text { Coefficient } \\
\text { estimated }\end{array}$ & $\begin{array}{l}\text { Standard } \\
\text { error }\end{array}$ & F-value & P-value & $\begin{array}{l}\text { Coefficient } \\
\text { estimated }\end{array}$ & $\begin{array}{l}\text { Standard } \\
\text { error }\end{array}$ & F-value & P-value \\
\hline Intercept & 96.02 & 0.31 & & & 97.33 & 0.37 & & \\
\hline \multicolumn{9}{|l|}{ Linear } \\
\hline $\mathrm{X}_{1}$ & 1.12 & 0.25 & 19.95 & 0.0004 & 1.70 & 0.30 & 33.02 & $<0.0001$ \\
\hline$X_{2}$ & 1.15 & 0.25 & 20.99 & 0.0003 & 0.76 & 0.30 & 6.62 & 0.0204 \\
\hline$X_{3}$ & 0.44 & 0.25 & 3.16 & 0.0944 & 1.11 & 0.30 & 14.09 & 0.0017 \\
\hline $\mathrm{X}_{4}$ & 1.39 & 0.25 & 30.87 & $<0.0001$ & 3.54 & 0.30 & 142.94 & $<0.0001$ \\
\hline \multicolumn{9}{|l|}{ Quadratic } \\
\hline $\mathrm{X}_{1}^{2}$ & -0.86 & 0.66 & 1.70 & 0.2103 & -1.05 & 0.78 & 1.80 & 0.1981 \\
\hline $\mathrm{X}_{2}^{2}$ & -0.08 & 0.66 & 0.01 & 0.9054 & 0.12 & 0.78 & 0.02 & 0.8769 \\
\hline $\mathrm{X}_{3}^{2}$ & -0.13 & 0.66 & 0.04 & 0.8466 & -0.63 & 0.78 & 0.65 & 0.4336 \\
\hline$X_{4}^{2}$ & -1.91 & 0.66 & 8.38 & 0.0105 & -2.23 & 0.78 & 8.19 & 0.0113 \\
\hline \multicolumn{9}{|l|}{ Interaction } \\
\hline $\mathrm{X}_{1} \mathrm{X}_{2}$ & -1.08 & 0.27 & 16.63 & 0.0009 & -0.10 & 0.31 & 0.11 & 0.7501 \\
\hline $\mathrm{X}_{1} \mathrm{X}_{3}$ & -0.68 & 0.27 & 6.49 & 0.0215 & 0.37 & 0.31 & 1.37 & 0.2595 \\
\hline $\mathrm{X}_{1} \mathrm{X}_{4}$ & -2.57 & 0.27 & 93.76 & $<0.0001$ & -1.95 & 0.31 & 38.66 & $<0.0001$ \\
\hline $\mathrm{X}_{2} \mathrm{X}_{3}$ & -0.88 & 0.27 & 11.09 & 0.0042 & -0.26 & 0.31 & 0.69 & 0.4191 \\
\hline $\mathrm{X}_{2} \mathrm{X}_{4}$ & -1.14 & 0.27 & 18.34 & 0.0006 & -0.61 & 0.31 & 3.77 & 0.0701 \\
\hline $\mathrm{X}_{3} \mathrm{X}_{4}$ & -0.64 & 0.27 & 5.76 & 0.0289 & -0.85 & 0.31 & 7.28 & 0.0158 \\
\hline
\end{tabular}

Table 3: The analysis of variance (ANOVA) and estimated regression coefficients for the product yield and the FAME yield models.

\begin{tabular}{|c|c|c|c|c|}
\hline & $\begin{array}{c}\text { Model } \\
\text { F value }\end{array}$ & Prob>F & Lack of fit & Rdj R-Square \\
\hline Product yield & 19.89 & $<0.0001$ & 0.0521 & 0.9457 \\
\hline FAME yield & 21.93 & $<0.0001$ & 0.3321 & 0.9981 \\
\hline
\end{tabular}

Table 4: The fit summary of the product yield and the FAME yield regression models.

\section{Effect of process parameters and optimization}

Effect of linear and quadratic model terms: It has been proven that a positive model term coefficient reveals the synergistic effect while a negative term implies the antagonistic effect in a transesterification process [27]. As the linear regression coefficients of the reaction temperature, reaction time, molar ratio of methanol/oil and catalyst concentration as presented in Table 3, were positive, all of these four independent factors exhibited the enhancement on the product yield and FAME yield. As for the p-value of each model term, the lower it is, the more significant the model term is to its regression model $[17,29]$. For this study, in the product yield regression model, only the molar ratio of methanol/oil was a non-significant model term as its p-value of 0.094 was greater than 0.05 . The order of the significance of its linear-model terms was: catalyst concentration $>$ time $>$ temperature $>$ molar ratio of methanol to oil. For the FAME yield, the p-values of all four factors were less than 0.05 , implying their significant contributions to the yield increase. The order of the significance of the linear terms in the FAME yield regression model was: catalyst concentration $>$ temperature $>$ molar ratio of methanol to oil >time. From these observations, it is obvious that catalyst concentration was the primary determining factor impacting both the camelina biodiesel product yield and the FAME yield. This is in agreement with research conducted by Wu and Leung [17], in which an orthogonal experimental design was used to optimize biodiesel production from camelina oil. Bautista et al. [30] also reported that $\mathrm{KOH}$ catalyst concentration was the most important factor for both the product and FAME yields of biodiesel derived from used cooking oil. As for the quadratic model terms, both the product yield and the FAME yield were significantly influenced only by the square of the catalyst concentration $\left(\mathrm{X}_{4}^{2}\right)$ and much less by other factors such as temperature, time, and molar ratios of methanol/oil.
The interaction effect on the product yield: As seen from Table 3, the $\mathrm{p}$-values of all of the interaction terms in product yield regression model were less than 0.05 , indicating that the interaction between the independent factors significantly influenced the camelina biodiesel product yield within the experimental range. Their negative coefficients resulted in the negative contributions to the product yield. The interaction between the catalyst concentration and the temperature was the most significant one among these six interaction terms, with the lowest $\mathrm{p}$-value $<0.0001$ and the highest estimated coefficient of -2.57 . Figure 2 plotted the response, product yield, as a function of two factors at one time while keeping the other two factors at a constant central point level in a three-dimensional response surface with the contour plot at the bottom.

Figure $2 \mathrm{~A}$ plots the product yield as a function of the catalyst concentration and temperature, and shows a strong interaction between these two factors. It clearly shows that increasing catalyst concentration at a relatively low temperature range $\left(<40^{\circ} \mathrm{C}\right)$ led to a significant increase in biodiesel product yield from approximately $88 \%$ to $96 \%$. However, when the reaction temperature was at a relatively high level, the addition of catalyst over $1.25 \mathrm{wt} . \%$ resulted in a decline in the product yield. Similar patterns were observed when increasing temperature at relatively low or high catalyst concentrations. Therefore, a significant interaction between catalyst concentration and temperature existed.

Figure $2 \mathrm{~B}$ presents the interaction effect between the reaction time and the catalyst concentration. Increasing the reaction time from 20 min to 40 min induced the product yield increment from $90 \%$ to $97 \%$ when the catalyst concentration was at low levels. When the catalyst concentration was increased to the range of $1.3 \mathrm{wt} . \%$ to $1.75 \mathrm{wt} . \%$, the product yield did not remarkably increase with the increased time. Therefore, the catalyst concentration and the time interacted with each 


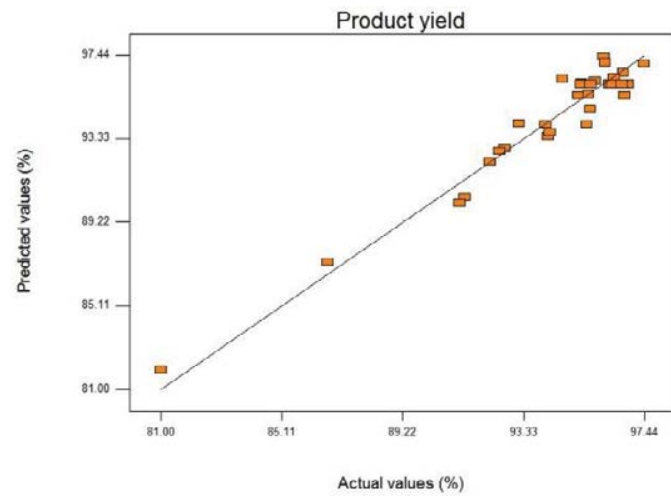

(a)

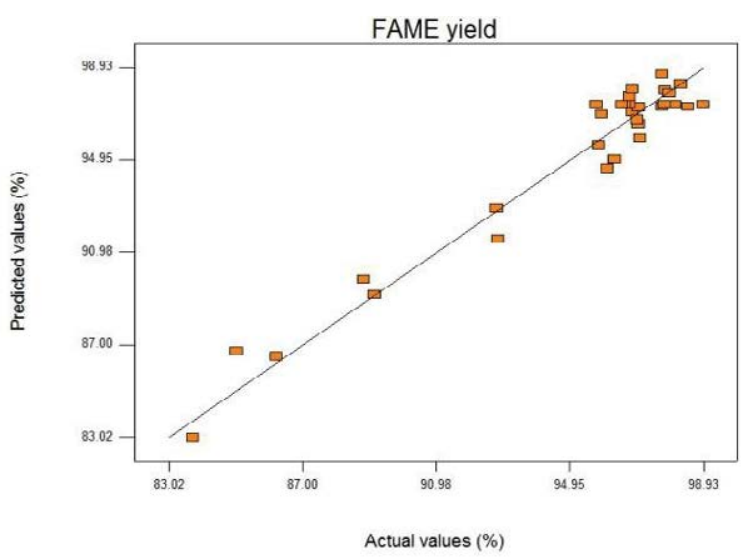

(b)

Figure 1: (a) Actual values vs. predicted values for product yield. (b) Actual values vs. predicted values for FAME yield.

(A) Time $=30 \mathrm{~min} ;$ Molar ratio $=8: 1$

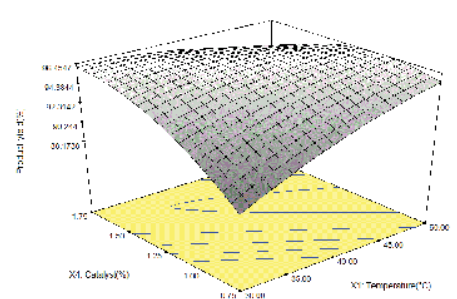

(C) Catalyst $=1.25 \mathrm{wt} . \%$; Molar ratio $=8: 1$

(D) Catalyst $=1.25 \mathrm{wt} . \%$; Temperature $=40^{\circ} \mathrm{C}$

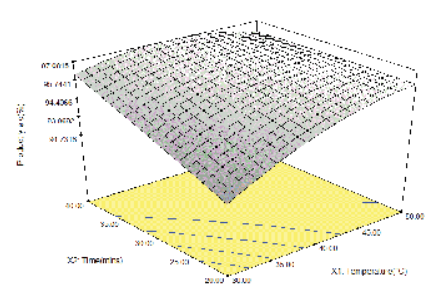

(E) Catalyst $=1.25 \mathrm{wt} \%$; Time $=30 \mathrm{~min}$

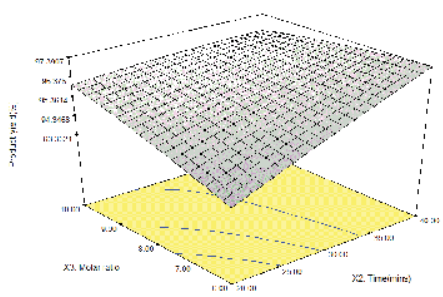

(F) Temperature $=40^{\circ} \mathrm{C}$; Time $=30 \mathrm{~min}$
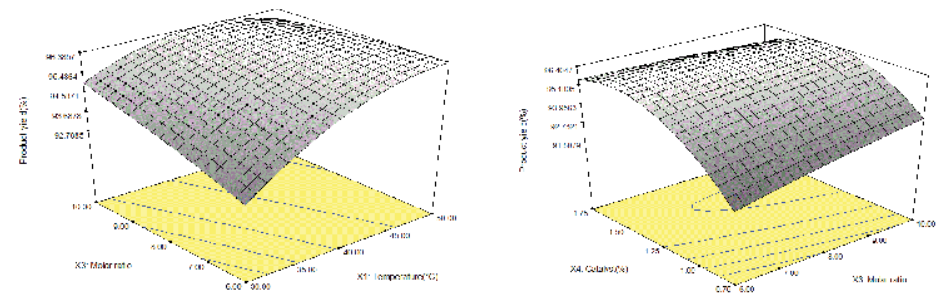

Figure 2: The response surface plot of the camelina biodiesel product yield at different levels of experimental factors. (A) catalyst concentration and temperature; (B) catalyst concentration and time; (C) temperature and time; (D) time and molar ratio; (E) temperature and molar ratio; (F) catalyst and molar ratio. 
other during the transesterification process and generated a significantly negative impact on the camelina biodiesel product yield ( $\mathrm{p}$-value of 0.0006; estimated coefficient of -1.14). This observation is consistent with other studies [29], which also reported that the interaction between the catalyst $(\mathrm{NaOH})$ concentration and the reaction time significantly decreased the product yield of biodiesel derived from cottonseed oil. Comparable interaction patterns were observed as well from Figure $2 \mathrm{C}-2 \mathrm{~F}$. In this study, therefore, it is safe to draw the conclusion that the product yield of camelina biodiesel was significantly impacted and decreased by the interactions between experimental factors.

Interaction effect on the FAME yield: Unlike the product yield, which was significantly affected by all of the six possible interactions between the independent factors, FAME yield was remarkably influenced only by two interactions, namely the interaction between the catalyst concentration and the temperature (p-value $<0.0001)$ and the interaction between the catalyst concentration and the molar ratio of methanol/oil ( $p$-value of $0.0158<0.05$ ). The interaction between the catalyst concentration and the temperature impacted the FAME yield negatively as shown in Figure 3A. Figure 3B illustrated the effect resulting from the interaction between the catalyst and the molar ratio. The FAME yield was continuously increased from $88 \%$ to $95 \%$ with the increase of the molar ratio in the range of low catalyst concentration. When the catalyst concentration was relatively high (>1.25 wt.\%), increasing molar ratio of methanol/oil from 6:1 to 8:1 led to an increase in the FAME yield, but a further increase of the molar ratio slightly reduced the FAME yield.

Compared to Figure 3A and 3B, Figure 3C-3F showed very different interaction patterns. For instance, Figure $3 \mathrm{C}$ exhibited a non-significant interaction between the time and temperature. The FAME yield was continuously raised by increasing time at any point of temperature within the experimental scope. The increase in the temperature also led to the FAME yield improvement when the reaction time was in the range of $20 \mathrm{~min}$ to $40 \mathrm{~min}$. Therefore, there was a weak interaction between the time and temperature, and a negligibly negative effect of it on the FAME yield.

\section{Optimization of biodiesel yields based on the developed models}

Aiming to achieve the maximum camelina biodiesel product and FAME yields, the optimal reaction conditions were determined by Design Expert as follows: reaction temperature of $38.7^{\circ} \mathrm{C}$, reaction time of $40 \mathrm{~min}$, molar ratio of methanol/oil of 7.7 and catalyst concentration

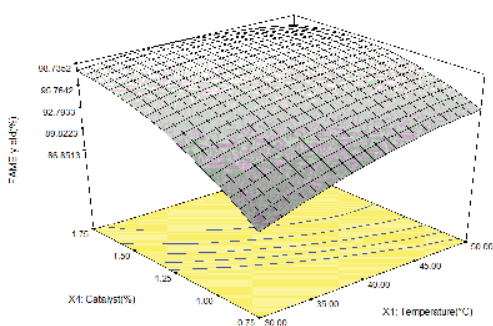

(C) Catalyst $=1.25$ wt. $\%$; Molar ratio $=8: 1$

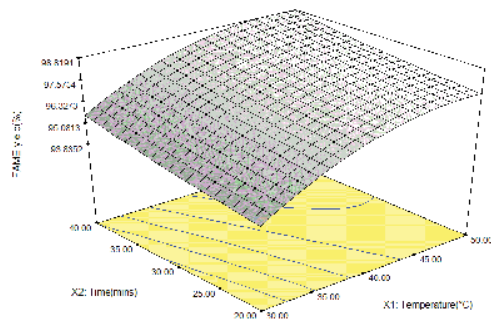

(E) Temperature $=40^{\circ} \mathrm{C}$; Catalyst $=1.25 \mathrm{wt} . \%$

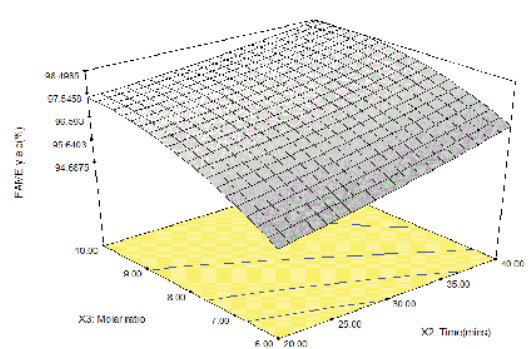

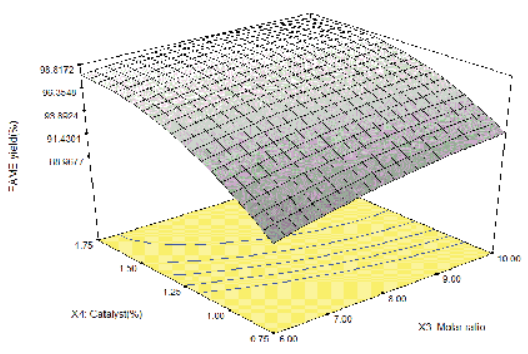

(D) Catalyst $=1.25 \mathrm{wt} . \%$; Time $=30 \mathrm{~min}$

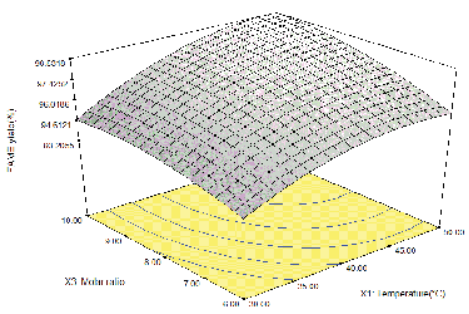

(F) Temperature $=40^{\circ} \mathrm{C}$; Molar ratio $=8: 1$

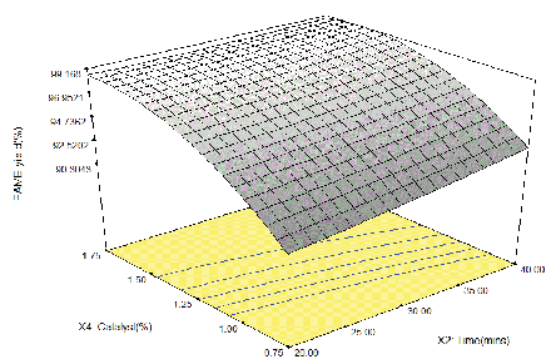

Figure 3: The response surface plot of the camelina biodiesel FAME yield at different levels of experimental factors. (A) catalyst concentration and temperature; (B) catalyst concentration and molar ratio; $(C)$ temperature and time; $(D)$ temperature and molar ratio; $(E)$ time and molar ratio; $(F)$ catalyst concentration and time. 
Citation: Yang J, Corscadden K, He QS, Caldwell C (2015) The Optimization of Alkali-Catalyzed Biodiesel Production from Camelina sativa Oil Using a Response Surface Methodology. J Bioprocess Biotech 5: 235 doi:10.4172/2155-9821.1000235

Page 7 of 8

\begin{tabular}{|c|c|c|c|c|c|c|c|}
\hline Feedstock & $\begin{array}{c}\text { Temp } \\
\left({ }^{\circ} \mathbf{C}\right)\end{array}$ & $\begin{array}{c}\text { Time } \\
(\mathbf{m i n})\end{array}$ & Molar ratio & $\begin{array}{c}\text { Catalyst } \\
(\mathbf{w t} . \mathbf{0})\end{array}$ & $\begin{array}{c}\text { Product yield } \\
\mathbf{( \% )}\end{array}$ & FAME yield (\%) & Reference \\
\hline Rapeseed & 65 & 120 & $6: 1$ & $\mathrm{KOH}: 1.0$ & $95-96$ & - \\
\hline Sunflower & 60 & 120 & $6: 1$ & $\mathrm{NaOH}: 1.0$ & 97.1 & - \\
\hline Canola & 60 & 60 & $9: 1$ & $\mathrm{KOH}: 1.0$ & $80-95$ & - \\
\hline UFO & 60 & 20 & $7: 1$ & $\mathrm{NaOH}: 1.1$ & 88.8 & - & {$[31]$} \\
\hline Camelina & 50 & 70 & $8: 1$ & $\mathrm{KOH}: 1.0$ & 95.8 & 98.4 & {$[32]$} \\
\hline Camelina & 38.7 & 40 & $7.7: 1$ & $\mathrm{KOH}: 1.5$ & 97 & 98.9 & \\
\hline
\end{tabular}

Note: UFO: Used Cooking Oil; Temp: Temperature; Molar ratio: molar ratio of methanol to oil; Catalyst: catalyst concentration. KOH: Potassium hydroxide; NaOH: Sodium hydroxide.

Table 5: Comparison among various studies on alkali-catalyzed transesterification of different feedstock.

of 1.5 wt.\% with respect to raw oil. The predicted camelina biodiesel product yield and FAME yield were $97 \%$ and $98.9 \%$, respectively. Experiments were conducted in duplicate under such optimized conditions. A good agreement between the experimental and modeldetermined values was achieved, which further confirmed the accuracy of the developed regression models.

\section{Comparison between this study and studies reported in literature}

To the best of our knowledge, this study is the first one that optimized alkali-catalyzed camelina biodiesel synthesis using response surface methodology. It is worth to compare the result to results reported in literature using other feedstock such as canola, sunflower and used cooking oil $[20,21,31,32]$ as well as alternative optimization methodology [17]. As shown in Table 5, the optimal reaction condition obtained from the present study resulted in relatively high product and FAME yield with the lowest applied temperature and largest catalyst consumption.

\section{Conclusions}

RSM was an effective tool to optimize the alkali-catalyzed transesterification of camelina oil under different reaction conditions (temperature, time, molar ratio of methanol/oil and catalyst concentration). Mathematical regression models of the camelina biodiesel product yield and FAME yield were developed. ANOVA analysis verified the validity of the developed regression models, and also demonstrated that the catalyst concentration was the most significant factor for both product yield and FAME yield. The optimal conditions were determined to be a reaction temperature of $38.7^{\circ} \mathrm{C}, 40$ min of reaction time, 7.7 of molar ratio of methanol/oil, and $1.50 \mathrm{wt} . \%$ of catalyst concentration. At such optimal conditions, the maximum camelina biodiesel product yield of $97 \%$ and FAME yield of $98.9 \%$ were achieved.

\section{Acknowledgments}

The authors would like to acknowledge the financial support from the Department of Agriculture, Nova Scotia, through the Growing Forward 2 Research Acceleration Program. The authors are grateful to Jili Li for the GC operation, Dr Ashutosh Singh for his assistance with statistical analysis and David Gibson for the biodiesel synthesis.

\section{References}

1. Bankovic-Ilic IB, Stamenkovic OS, Veljkovic VB (2012) Biodiesel production from non-edible plant oils. Renew Sust Energy Rev 16: 3621-3647.

2. Krohn BJ, Fripp M (2012) A life cycle assessment of biodiesel derived from the "niche filling" energy crop camelina in the USA. Appl Energy 92: 92-98.

3. EIA (2010) US Energy Information Agency. Annual energy outlook 2010: With projections to 2035. U.S. Energy Information Administration.

4. Xue J, Grift TE, Hansen AC (2011) Effect of biodiesel on engine performances and emissions. Renew Sust Energy Rev 15: 1098-1116.

5. Atabani AE, Silitonga AS, Badruddin IA, Mahlia TMI, Masjuki HH, et al. (2012) A comprehensive review on biodiesel as an alternative energy resource and its characteristics. Renew Sust Energy Rev 16: 2070-2093.

6. Gui MM, Lee KT, Bhatia S (2008) Feasibility of edible oil vs. non-edible oil vs. waste edible oil as biodiesel feedstock. Energy 33: 1646-1653.

7. Serra T, Zilberman D (2013) Biofuel-related price transmission literature: A review. Energy Economics 37: 141-151.

8. Abdulla R, Ravindra P (2013) Immobilized Burkholderia cepacia lipase for biodiesel production from crude Jatropha curcas L. oil. Biomass Bioenergy 56 : 8-13.

9. Moser BR, Vaughn SF (2010) Evaluation of alkyl esters from Camelina sativa oil as biodiesel and as blend components in ultra low-sulfur diesel fuel. Bioresour Technol 101: 646-653.

10. Urbaniak SD, Caldwell CD, Zheljazkov VD, Lada R, Luan L (2008) The effect of cultivar and applied nitrogen on the performance of Camelina sativa $\mathrm{L}$. in the Maritime Provinces of Canada. Can J Plant Sci 88: 111-119.

11. Zubr J (1997) Oil-seed crop: Camelina sativa. Ind Crops Prod 6: 113-119.

12. Gugel RK, Falk SK (2006) Agronomic and seed quality evaluation of Camelina sativa in western Canada. Can J Plant Sci 86: 1047-1058.

13. Jiang Y, Caldwell CD, Kevin KC (2014) Camelina seed quality in response to applied nitrogen, genotype and environment. Can J Plant Sci 94: 971-980.

14. Iskandarov U, Kim HJ, Cahoon EB (2014) Camelina: An emerging oilseed platform for advanced biofuels and bio-based materials. Plants and BioEnergy 4: $131-140$.

15. Kirkhus B, Lundon AR, Haugen JE, Vogt G, Borge Gl, et al. (2013) Effects of environmental factors on edible oil quality of organically grown Camelina sativa. J Agric Food Chem 61: 3179-3185.

16. Patil PD, Gude VG, Deng S (2009) Biodiesel production from Jatropha curcas waste cooking, and Camelina sativa oils. Ind Eng Chem Res 48: 10850-10856.

17. Wu X, Leung DY (2011) Optimization of biodiesel production from Camelina oil using orthogonal experiment. Appl Energy 88: 3615-3624.

18. Leung DY, Wu X, Leung MKH (2010) A review on biodiesel production using catalyzed transesterification. Appl Energy 87: 1083-1095.

19. Nigam PS, Singh A (2011) Production of liquid biofuels from renewable resources. Prog Energy Combust Sci 37: 52-68.

20. Rashid U, Anwar F (2008) Production of biodiesel through optimized alkalinecatalyzed transesterification of rapeseed oil. Fuel 87: 265-273.

21. Leung DYC, Guo Y (2006) Transesterification of neat and used frying oil: Optimization for biodiesel production. Fuel Process Technol 87: 883-890.

22. Mootabadi H, Salamatinia B, Bhatia S, Abdullah AZ (2010) Ultrasonic-assisted biodiesel production process from palm oil using alkaline earth metal oxides as the heterogeneous catalysts. Fuel 89: 1818-1825.

23. Awad S, Paraschiv M, Varuvel EG, Tazerout M (2013) Optimization of biodiese production from animal fat residue in wastewater using response surface methodology. Bioresour Technol 129: 315-320.

24. Omar WNNW, Amin NAS (2011) Optimization of heterogeneous biodiese production from waste cooking palm oil via response surface methodology. Biomass Bioenergy 35: 1329-1338. 
Citation: Yang J, Corscadden K, He QS, Caldwell C (2015) The Optimization of Alkali-Catalyzed Biodiesel Production from Camelina sativa Oil Using a Response Surface Methodology. J Bioprocess Biotech 5: 235 doi:10.4172/2155-9821.1000235

25. Box GEP, Draper NR (1987) Empirical model-building and response surfaces. Wiley Publishers, New York, USA

26. Myers RH, Montgomery DC, Anderson-Cook CM (2009) Response surface methodology: Process and product optimization using designed experiments. John Wiley \& Sons, USA

27. Jaliliannosrati H, Amin NA, Talebian-Kiakalaieh A, Noshadi I (2013) Microwave assisted biodiesel production from Jatropha curcas L. seed by two-step in situ process: optimization using response surface methodology. Bioresour Technol 136: 565-573.

28. Ceylan H, Kubilay S, Aktas N, Sahiner N (2008) An approach for prediction of optimum reaction conditions for laccase-catalyzed bio-transformation of 1-naphthol by response surface methodology (RSM). Bioresour Technol 99: 2025-2031.
29. Fan X, Chen F, Wang X (2010) Ultrasound-assisted synthesis of biodiesel from crude cottonseed oil using response surface methodology. J Oleo Sci 59: 235 241.

30. Bautista LF, Vicente G, Rodriguez R, Pacheco M (2009) Optimisation of FAME production from waste cooking oil for biodiesel use. Biomass Bioenergy 33 862-872.

31. Rashid U, Anwar F, Moser BR, Ashraf S (2008) Production of sunflower oil methyl esters by optimized alkali-catalyzed methanolysis. Biomass Bioenergy 32: 1202-1205.

32. Patil PD, Deng S (2009) Optimization of biodiesel production from edible and non-edible vegetable oils. Fuel 88: 1302-1306 